\title{
PENGARUH PENDIDIKAN KESEHATAN DENGAN METODE PEER GROUP TERHADAP PENGETAHUAN REMAJA PUTRI TENTANG PERSONAL HYGIENE
}

(The Effect of Health Education with Peer Group Method of Princess Adolescent About Personal Hygiene)

\author{
Domas Nurchandra Pramudianti, Mirawati, Fika Aulia \\ Dosen Kebidanan Universitas Muhammadiyah Banjarmasin \\ domaschandra89@gmail.com
}

\begin{abstract}
ABSTRAK
Kesehatan reproduksi merupakan keadaan sehat secara fisik, mental dan sosial secara utuh, tidak sematamata bebas dari penyakit atau kecacatan yang berkaitan dengan sistem, fungsi dan proses reproduksi. Kesehatan reproduksi di kalangan wanita merupakan masalah yang penting untuk diperhatikan. Masalah kesehatan organ reproduksi pada remaja perlu mendapat perhatian yang serius, karena masalah tersebut paling sering muncul pada negara-negara berkembang termasuk Indonesia. Sering kali remaja mengabaikan pentingnya berperilaku sehat terutama dalam menjaga organ vagina agar terhindar dari berbagai penyakit yang sering dijumpai pada kesehatan organ vagina. Penelitian ini bertujuan untuk mengetahui pengaruh Pendidikan kesehatan dengan metode peer group terhadap pengetahuan remaja putri tentang personal hygiene. Jenis penelitian ini menggunakan penelitian kuantitatif dengan rancangan Quasi Eksperimen (eksperimen semu) dengan pre-post with control group designSampel dalam penelitian ini didapatkan pada bulan Juni berjumlah 30 orang siswi yang ada di SMP Muhammadiyah 1 Banjarmasin dan dibagi menjadi 2 kelompok, terdapat 15 orang responden masuk kelompok intervensi dan 15 orang masuk kelompok kontrol. Analisis data menggunakan uji "Wilcoxon Signed Rank Test" yaitu untuk mengetahui perbedaan (komparasi) antara sebelum dan sesudah dengan menggunakan skala data ordinal. Hasil penelitian membuktikan bahwa terdapat pengaruh Pendidikan kesehatan terhadap pengetahuan personal hygiene pada remaja putri dengan $\rho$ value $=0,001$. Dari hasil penelitian dapat disimpulkan bahwa ada pengaruh Pendidikan Kesehatan dengan metode Peer Group Terhadap Pengetahuan Personal Hygiene Remaja Putri dibuktikan dengan adanya perbedaan nilai pengetahuan personal hygiene antara sebelum dan sesudah diberikan pendidikan kesehatan dengan metode peer group pada kelompok intervensi
\end{abstract}

Kata Kunci : Pendidikan kesehatan Peer Group, Pengetahuan Personal hygiene

\section{ABSTRACT}

Reproductive health is a state of physical health, mental and social as a whole, not solely free from diseases or disabilities related to the reproductive system, functions and processes. Reproductive health among women is an important issue to consider. Reproductive organ health problems in adolescents need to get serious attention, because these problems most often arise in developing countries including Indonesia. Often adolescents ignore the importance of healthy behavior, especially in maintaining the vaginal organs to avoid various diseases that are often found in the health of the vaginal organs. This study aims to determine the effect of health education with peer group methods on young women's knowledge about personal hygiene. This type of research uses quantitative research with Quasi Experiment design (quasi-experimental) with pre-post with control group design. Samples in this study were obtained in June totaling 30 students in SMP Muhammadiyah 1 Banjarmasin and divided into 2 groups, there were 15 respondents in the intervention group and 15 in the control group. Data analysis using the "Wilcoxon Signed Rank Test" is to find out the difference (comparison) between before and after using ordinal data scale. The results of the study prove that there is an influence of health education on personal hygiene knowledge in young women with $\rho$ value $=0.001$. From the results of the study it can be concluded that there is an effect of Health Education with the Peer Group method on Personal Hygiene Knowledge for 
Young Women is evidenced by the difference in the value of personal hygiene knowledge between before and after being given health education by the peer group method in the intervention group

\section{Keywords: Peer Group health education, Personal hygiene knowledge}

\section{PENDAHULUAN}

Masa remaja merupakan salah satu periode dari perkembangan manusia dimana pada masa ini terjadi suatu perubahan baik biologis, psikologis maupun social. Perubahan yang terjadi pada remaja putri ditandai dengan menarche (haid pertama), perubahan pada dada, tumbuhnya rambut kemaluan dan juga pembesaran panggul (Estiwidani et al.,2009). Fungsi yang akan dijalankan dalam proses pertumbuhan tersebut tidak dapat dilakukan bila organ-organ tidak terawat sejak awal (Kerala State AIDS Control Society, 2012). Gangguan pada masa remaja seringkali diakibatkan oleh pola hidup remaja.

Menurut Murti \& Lutfiyati (2017) kesehatan reproduksi di kalangan wanita merupakan masalah yang penting untuk diperhatikan. Masalah kesehatan organ reproduksi pada remaja perlu mendapat perhatian yang serius, karena masalah tersebut paling sering muncul pada negaranegara berkembang termasuk Indonesia (Nurhayati, 2013). Sering kali remaja mengabaikan pentingnya berpengetahuan sehat terutama dalam menjaga organ vagina agar terhindar dari berbagai penyakit yang sering dijumpai pada kesehatan organ vagina.

Masalah remaja dengan organ reproduksinya kurang mendapatkan perhatian karena umur relatif muda, masih dalam status pendidikan sehingga seolaholah bebas dari kemungkinan menghadapi masalah penyulit dan penyakit yang berkaitan dengan alat reproduksinya (Suriani \& Hermansyah, 2014). Padahal banyak sekali penyakit yang dapat terjadi jika kita tidak menjaga dan membersihkan organ vagina dengan benar, itu sebabnya penting memahami dan mengetahui tentang kebersihan organ vagina.

Pada penelitian Mokodongan (2015) menyatakan bahwa lebih banyak remaja memiliki risiko tinggi akan mengalami masalah kesehatan reproduksi, ada $10 \%$ remaja yang sering menggunakan produk pembersih wanita, ada $17,59 \%$ remaja yang tidak mengeringkan genitalia eksterna setelah buang air kecil atau buang air besar dengan menggunakan tisu atau handuk kering. Selanjutnya $25,76 \%$ remaja yang membersihkan genitalia eksterna dengan arah dari belakang ke depan, $17 \%$ remaja 
yang sering menggunakan celana dalam ketat dalam aktivitas sehari-hari. 8,2\% remaja yang sering memakai celana dalam dengan bahan bukan katun 2,5\%remaja yang sering memakai bersama pakaian dalam dan handuk dengan orang lain (Abrori et al., 2017).

Pada remaja yang kurang informasi tentang kebersihan organ genetalia akan berdampak pula pada perilaku remaja dalam menjaga kebersihan organ genetalianya (Nanlessy et al., 2013). Perilaku seseorang biasanya dicerminkan dengan sikap, bagaimana seseorang bersikap dan berbuat dalam perilaku membersihkan organ vagina itu dapat menentukan kebersihan vagina itu sendiri.

Penanganan yang dilakukan untuk mencegah masalah kesehatan reproduksi remaja salah satunya pendekatan pada kelompok sebaya (peer group). Kuatnya pengaruh kelompok sebaya (peer group) dikarenakan remaja lebih banyak berada diluar rumah bersama dengan teman-teman sebaya sebagai kelompok (Suriani \& Hermansyah 2014). Remaja seringkali bercerita masalah kesehatan reproduksinya hanya dengan teman sebayanya dan tidak bercerita kepada orang tua, karena sering menghabiskan waktu bersama saat di sekolah dan saat bermain dari pada dengan orang tua, disitu lah peran teman sebaya sangat berperan saat remaja memiliki masalah seputar masalah kesehatan reproduksi. Alasan lain dari remaja lebih nyaman bercerita masalah kesehatan reproduksi dengan teman sebaya karena remaja malu menceritakan dengan orang tua. Tujuan penelitian ini adalah untuk mengetahui pengaruh Pendidikan kesehatan peer group terhadap pengetahuan remaja putri tentang personal hygiene.

\section{METODE}

Jenis penelitian ini menggunakan penelitian kuantitatif dengan rancangan Quasi Eksperimen (eksperimen semu) dengan prepost with control group design. Rancangan ini merupakan rancangan dengan memberikan pre-test (pengamatan awal) untuk mengetahui pengetahuan personal hygiene remaja menggunakan kuesioner sebelum diberikan intervensi atau perlakuan, setelah itu diberikan perlakuan berupa Pendidikan kesehatan peer group pada kelompok intervensi dan kelompok kontrol diberikan leaflet kemudian dilakukan post-test (pengamatan akhir) (Nursalam, 2014: 166). Sampel dalam penelitian ini didapatkan pada bulan Juni berjumlah 30 orang siswi yang ada di SMP Muhammadiyah 1 Banjarmasin dan dibagi menjadi 2 kelompok, terdapat 15 orang responden masuk kelompok intervensi dan 15 orang masuk kelompok kontrol. 
Analisis data menggunakan analisis univariat dan bivariat. Analisa univariat digunakan untuk mendeskripsikan variabel dependent (Pengetahuan personal hygiene) dan independent (pendidikan kesehatan dengan untuk mengetahui pengaruh pendidikan kesehatan peer group terhadap pengetahuan tentang personal hygiene pada remaja putri. Analisis bivariat menggunakan uji "Wilcoxon Signed Rank Test" yaitu untuk mengetahui perbedaan (komparasi) antara sebelum dan sesudah dengan menggunakan skala data ordinal (Hidayat, 2014: 122).

Kriteria pengaruh variabel ditentukan ditentukan oleh nilai $p$ value. Apabila nilai $p$ $\leq$ a 0,05 , maka Ho ditolak dan Ha diterima berarti ada pengaruh antara variabel independent dengan variabel dependent. Apabila $p>a$ 0,05 maka Ho diterima berarti tidak ada pengaruh antara variabel independent dengan variabel dependent. Perhitungan analisis data menggunakan software SPSS pada tingkat kepercayaan yang diinginkan peneliti sebanyak 95\% $p$ value 0,05 .

\section{HASIL}

1. Analisis Univariat

Tabel 1.1 Pengetahuan Personal Hygiene Sebelum diberikan Perlakuan Pada Kelompok Kontrol dan Intervensi

\begin{tabular}{|c|c|c|c|c|c|}
\hline \multirow{2}{*}{ No. } & \multirow{2}{*}{$\begin{array}{c}\text { Pengetahuan } \\
\text { Personal Hygiene } \\
\text { Sebelum Diberikan } \\
\text { Perlakuan }\end{array}$} & \multicolumn{2}{|c|}{$\begin{array}{l}\text { Kelompok } \\
\text { Intervensi }\end{array}$} & \multicolumn{2}{|c|}{$\begin{array}{c}\text { Kelompok } \\
\text { Kontrol }\end{array}$} \\
\hline & & $\mathrm{F}$ & $\%$ & $\mathrm{f}$ & $\%$ \\
\hline 1. & Baik & 8 & 53,33 & 7 & 46,67 \\
\hline 2. & Kurang & 7 & 46,67 & 8 & 53,33 \\
\hline & Jumlah & 15 & 100 & 15 & 100 \\
\hline
\end{tabular}

Berdasarkan tabel 1,1 menunjukkan bahwa pengetahuan Personal Hygiene remaja putri pada kelompok intervensi kategori baik sebelum diberikan perlakuan sebanyak 8 responden $(53,33 \%)$ sedangkan pada kelompok kontrol kategori baik sebanyak 7 responden $(46,67 \%)$.

\begin{tabular}{|c|c|c|c|c|c|}
\hline \multirow{2}{*}{ No } & \multirow{2}{*}{$\begin{array}{c}\text { Pengetahuan } \\
\text { Personal } \\
\text { Hygiene Sesudah } \\
\text { Diberikan } \\
\text { Perlakuan } \\
\end{array}$} & \multicolumn{2}{|c|}{$\begin{array}{l}\text { Kelompok } \\
\text { Intervensi }\end{array}$} & \multicolumn{2}{|c|}{$\begin{array}{c}\text { Kelompok } \\
\text { Kontrol }\end{array}$} \\
\hline & & $\mathrm{f}$ & $\%$ & $\mathrm{f}$ & $\%$ \\
\hline 1. & Baik & 15 & 100 & 11 & 73,33 \\
\hline 2. & Kurang & 0 & 0 & 4 & 26,67 \\
\hline & Jumlah & 15 & 100 & 15 & 100 \\
\hline
\end{tabular}

Tabel 1.2 Gambaran Pengetahuan Personal Hygiene Sesudah diberikan Perlakuan Pada Kelompok Kontrol dan Intervensi

Berdasarkan tabel 1.2 menunjukkan bahwa pengetahuan Personal Hygiene remaja putri pada kelompok intervensi kategori baik sesudah diberikan perlakuan sebanyak 15 responden (100\%) sedangkan pada kelompok kontrol kategori baik sebanyak 11 responden $(73,33 \%)$.

\section{Analsisis bivariat}

Tabel 1.3 Pengaruh Pemberian Pendidikan Kesehatan dengan Metode Peer Group terhadap Pengetahuan Personal Hygiene pada Remaja Putri

Berdasarkan hasil uji Wilcoxon pada kelompok intervensi di dapatkan nilai $\rho=$ $0,001(\rho<\alpha)$ yang artinya $H_{\circ}$ ditolak sehingga 
dapat disimpulkan bahwa Ada Pengaruh antara Pendidikan kesehatan Peer group dengan pengetahuan personal hygiene.

\section{PEMBAHASAN}

1. Gambaran Pengetahuan Personal Hygiene Sebelum diberikan Perlakuan pada Kelompok Intervensi

Dari hasil penelitian yang telah dilakukan pada kelompok intervensi didapatkan hasil 8 responden $(53,33 \%)$ pengetahuan personal hygiene remaja putri dengan kategori baik sebelum diberikan perlakuan pada kelompok intervensi.

Pada penelitian sebelum diberikan perlakuan dari 15 responden terdapat 8 responden yang pengetahuan personal hygiene remaja putri baik, dari hasil kuesioner yang telah diisi oleh responden didapatkan bahwa pada parameter perawatan kulit dan wajah, sebagian besar remaja putri membasuh wajah tiga kali sehari untuk mencegah jerawat. Pada parameter mandi, remaja putri mandi sudah sesuai yaitu dua kali sehari tiap pagi dan sore hari. Pada parameter perawatan diri pada kaki dan kuku, sebagian besar remaja putri selalu mengkikir kukunya agar tidak tajam setelah melakukan pemotongan kuku. Pada parameter perawatan rambut, remaja putri cukup banyak mencuci rambut paling tidak minimal dua kali dalam seminggu dan remaja menyisir rambut kurang lebih 4 kali sehari. Pada parameter perawatan gigi dan mulut, remaja putri banyak menggosok gigi 2 kali sehari setiap pagi dan malam sebelum tidur. Pada parameter penggunaan pakaian dalam, sebagian remaja putri mengganti celana dalam dua kali sehari setelah mandi. Pada parameter penggunaan handuk, sebagian besar remaja putri menjemur handuk setelah mereka mandi. Pada parameter memotong bulu pubis, hanya sedikit remaja putri yang memotong bulu pubis sebulan sekali untuk mencegah bakteri pada organ genitalia.

Pada parameter kebersihan alat kelamin luar, sebagian remaja tau bahawa setelah $B A B$ dan $B A K$ jangan langsung menggunakan pakaian dalam dan harus dikeringkan terlebih dahulu dan hanya beberapa remaja putri yang membasuh organ genitalia dari depan ke belakang. Pada parameter penggunaan pembalut wanita, sebagian remaja putri yang mengganti pembalut 4-5 kali sehari saat menstruasi dan sebagian menggunakan pantylinner saat keputihan atau sesuai kebutuhan. Sebagaimana yang dikemukakan oleh Tarwoto et al., (2012) cara pemeliharaan organ reproduksi pada perempuan, yaitu setiap setelah buang air kecil atau besar dan mengeringkan sampai benar-benar kering sebelum mengenakan pakaian dalam dan cara membersihkan vulva dari arah depan ke belakang adalah pengetahuan benar. Gunakan air bersih atau air mengalir. Pembalut saat menstruasi harus diganti 
secara teratur 4-5 kali. Jenis pembalut disesuaikan dengan kebutuhannya, misalnya pada saat menjelang haid dan mulai terasa adanya keputihan yang sifatnya fisiologis, bisa menggunakan pembalut yang berukuran kecil (pantylinner).

Penelitian ini sesuai dengan penelitian yang dilakukan oleh Nur (2018) terhadap 41 responden didapatkan $12,2 \quad \%$ berpengetahuan baik dan $39 \%$ berpengetahuan cukup baik. Pengetahuan ini dapat dipengaruhi oleh persepsi dan sikap seseorang. Apabila seseorang mempunyai persepsi dan sikap yang baik (positif) maka tidak selalu memiliki pengetahuan yang baik juga. Tapi seseorang yang mempunyai persepsi dan sikap yang buruk (negatif) maka akan berdampak buruk pada pengetahuannya. Pengetahuan merupakan aksi seseorang terhadap reaksi dari stimulus, dapat diartikan semua kegiatan atau aktivitas manusia yang diamati secara langsung maupun tidak langsung.

Ini sesuai dengan Jurnal Wijaya (2011) dalam Tulas et al., (2017) pengetahuan personal hygiene atau kebersihan diri adalah suatu usaha kesehatan perorangan untuk dapat memelihara kesehatan diri sendiri, memperbaiki dan mempertinggi nilai-nilai kesehatan serta mencegah timbulnya penyakit. Personal hygiene meliputi kebersihan badan, tangan, kulit / kuku, gigi dan rambut.
Pengetahuan personal hygiene remaja putri kategori baik sudah sesuai seperti pada keterangan diatas sebagian besar remaja putri berpengetahuan baik dalam menjaga kesehatan terutama pada organ reproduksi untuk mencegah berbagai penyakit. Sebagian besar remaja putri mengetahui bagaimana pengetahuan personal hygiene yang baik dan benar.

Pada penelitian Mokodongan (2015) dalam Abrori et al., (2017) menyatakan bahwa lebih banyak remaja memiliki risiko tinggi akan mengalami masalah kesehatan reproduksi, ada $10 \%$ remaja yang sering menggunakan produk pembersih wanita, ada $17,59 \%$ remaja yang tidak mengeringkan genitalia eksterna setelah buang air kecil atau buang air besar dengan menggunakan tisu atau handuk kering. Selanjutnya $25,76 \%$ remaja yang membersihkan genitalia eksterna dengan arah dari belakang ke depan, 17\% remaja yang sering menggunakan celana dalam ketat dalam aktivitas sehari-hari. 8,2\% remaja yang sering memakai celana dalam dengan bahan bukan katun 2,5\% remaja yang sering memakai bersama pakaian dalam dan handuk dengan orang lain.

Penelitian ini sesuai dengan hasil penelitian Nur (2018) terhadap 41 responden dimana didapatkan hasil sebanyak 16 responden (39\%) pengetahuan personal hygiene remaja putri cukup baik dan 20 responden $(48,8 \%)$ pengetahuan personal 
hygiene remaja putri kurang baik. Hasil penelitian menunjukkan sebagian besar remaja putri berpengetahuan kurang baik, karena mereka mempunyai kebiasaan yang kurang/buruk terhadap hygiene genitalia sehingga menyebabkan keputihan. Pengetahuan ini dapat dipengaruhi oleh persepsi dan sikap seseorang. Apabila seseorang mempunyai persepsi dan sikap yang baik (positif) maka tidak selalu memiliki pengetahuan yang baik juga. Tapi seseorang yang mempunyai persepsi dan sikap yang buruk (negatif) maka akan berdampak buruk pada pengetahuannya. Pengetahuan merupakan aksi seseorang terhadap reaksi dari stimulus, dapat diartikan semua kegiatan atau aktivitas manusia yang diamati secara langsung maupun tidak langsung.

Dari hasil penelitian menggunakan kuesioner didapatkan remaja putri mempunyai kebiasaan yang buruk terhadap personal hygiene terutama pada hygiene genitalia yang kurang diperhatikan kebersihannya. Pengetahuan personal hygiene yang buruk dapat berdampak pada kesehatan termasuk juga pada kesehatan reproduksi remaja seperti banyak penyakit yang dapat menyerang vagina karena kurangnya memperhatikan kebersihan genitalia.

2. Gambaran Pengetahuan Personal Hygiene Sesudah diberikan Perlakuan pada Kelompok Intervensi.
Dari hasil penelitian didapatkan 15 responden (100 \%) pengetahuan personal hygiene remaja putri dengan kategori baik sesudah diberikan pendidikan kesehatan pada kelompok intervensi. Pada penelitian sebelum diberikan perlakuan dari 15 responden terdapat 7 responden yang pengetahuan personal hygiene remaja putri buruk. Ternyata setelah diberikan pendidikan kesehatan dengan metode peer group pengetahuan personal hygiene remaja putri meningkat, dimana sebelum perlakuan masih ada 7 responden pengetahuan personal hygiene buruk, dan setelah pemberian peer group tidak terdapat lagi pengetahuan personal hygiene yang buruk.

Ternyata dengan pendidikan kesehatan metode peer group dapat meningkatkan pengetahuan personal hygiene remaja putri yang ada di SMA Negeri 5 Banjarmasin. Saat penelitian terlihat bahwa responden yang melakukan pendidikan kesehatan dengan metode peer group sangat aktif bercerita masalah kesehatan reproduksi yang telah mereka alami, seperti dalam jurnal Suriani \& Hermansyah (2014) yang mengatakan bahwa penanganan yang dilakukan untuk mencegah masalah kesehatan reproduksi remaja salah satunya pendekatan pada kelompok sebaya (peer group). Kuatnya pengaruh kelompok sebaya (peer group) dikarenakan remaja lebih banyak berada diluar rumah bersama dengan 
teman-teman sebaya sebagai kelompok. Peer group diharapkan mampu tumbuh menjadi peer educator yang diharapkan dapat membahas dan menangani permasalahan kesehatan reproduksi remaja. Institusi sekolah merupakan jalur yang sangat potensial untuk melatih peer group ini, karena institusi sekolah ini sangat mempengaruhi kehidupan dan pergaulan remaja.

Seperti yang dikemukakan Notoatmodjo (2007) dalam Jurnal Fatimah (2016) yaitu, pendidikan kesehatan adalah aplikasi atau penerapan pendidikan di dalam bidang kesehatan. Hasil (output) yang diharapkan dari suatu pendidikan kesehatan adalah pengetahuan kesehatan, atau pengetahuan untuk memelihara dan meningkatkan kesehatan yang kondusif. Peer group adalah salah satu ciri yang dibentuk dalam pengetahuan sosial dimana pengetahuan kelompok tersebut akan mempengaruhi pengetahuan serta nilai-nilai individu-individu yang menjadi anggotanya sehingga individu tersebut akan membentuk pola pengetahuan dan nilai-nilai yang baru.

Hal ini menunjukkan bahwa pendidikan kesehatan dengan metode peer group dapat memperbaiki pengetahuan personal hygiene remaja putri di karenakan pada saat penelitian responden lebih banyak sharing atau bercerita dengan kelompoknya tentang masalahmasalah kesehatan reproduksi yang mereka pernah alami dan mereka saling memberikan masukan atau saran yang membuat mereka memahami tentang bagaimana pengetahuan personal hygiene yang baik dan benar. Selain itu, karena mereka memiliki usia yang kurang lebih sama jadi memudahkan mereka untuk saling bercerita dan tidak malu ataupun risih saat bercerita.

Penelitian ini menunjukkan bahwa pendidikan kesehatan dengan metode peer group dapat diaplikasikan remaja putri untuk dapat berbagi pengalaman dan pengetahuan dalam meningkatkan kesehatan reproduksi khususnya dalam personal hygiene dari yang remaja tidak tau menjadi tau dan mengaplikasikan pengetahuan personal hygiene yang baik dalam kesehariannya.

3. Gambaran Pengetahuan Personal Hygiene Sebelum diberikan Perlakuan pada Kelompok Kontrol

Pada penelitian ini dari 15 responden terdapat 7 responden yang pengetahuan personal hygiene remaja putri baik, dari hasil kuesioner yang telah diisi oleh responden hampir sama dengan kelompok intervensi yaitu didapatkan bahwa pada parameter perawatan kulit dan wajah, sebagian besar remaja putri membasuh wajah tiga kali sehari untuk mencegah jerawat. Pada parameter mandi, remaja putri mandi sudah sesuai yaitu dua kali sehari tiap pagi dan sore hari. Pada parameter perawatan diri pada kaki dan kuku, sebagian besar remaja putri selalu mengkikir kukunya agar tidak tajam setelah melakukan 
pemotongan kuku. Pada parameter perawatan rambut, remaja putri cukup banyak mencuci rambut paling tidak minimal dua kali dalam seminggu dan remaja menyisir rambut kurang lebih 4 kali sehari. Pada parameter perawatan gigi dan mulut, remaja putri banyak menggosok gigi 2 kali sehari setiap pagi dan malam sebelum tidur. Pada parameter penggunaan pakaian dalam, sebagian remaja putri mengganti celana dalam dua kali sehari setelah mandi. Pada parameter penggunaan handuk, sebagian besar remaja putri menjemur handuk setelah mereka mandi. Pada parameter memotong bulu pubis, hanya sedikit remaja putri yang memotong bulu pubis sebulan sekali untuk mencegah bakteri pada organ genitalia. Pada parameter kebersihan alat kelamin luar, sebagian remaja tau bahawa setelah BAB dan BAK jangan langsung menggunakan pakaian dalam dan harus dikeringkan terlebih dahulu dan hanya beberapa remaja putri yang membasuh organ genitalia dari depan ke belakang. Pada parameter penggunaan pembalut wanita, sebagian remaja putri yang mengganti pembalut 4-5 kali sehari saat menstruasi dan sebagian menggunakan pantylinner saat keputihan atau sesuai kebutuhan.

Dari hasil penelitian menggunakan kuesioner pada kelompok kontrol pengetahuan personal hygiene buruk lebih banyak satu orang dibandingkan kelompok intervensi. Hal ini dilihat dari kuesioner pada parameter perawatan diri pada kaki dan kuku, remaja putri kurang mengetahui sebelum memotong kuku, kuku sebaiknya direndam air hangat kurang lebih 2 menit agar mengurangi bakteri yang ada pada kuku, seperti yang dikemukakan oleh Yuni (2015) rendam kuku dengan air hangat \pm 2 menit beri sabun jika kotor, potong kuku jangan terlalu dekat dengan ujung kulit, kemudian rapikan permukaan kuku dengan kikir kuku. Perawatan kaki dan kuku untuk mencegah infeksi, bau kaki, dan cedera jaringan lunak.

Pada parameter penggunaan celana dalam, sebagian remaja tidak tau bahan celana dalam yang dipakai mereka misal kaos, katun dan lainnya. Pada parameter kebersihan alat kelamin luar, hampir semua remaja tidak tau membasuh organ genitalia dari depan ke belakang dan sebagian remaja langsung memakai celana dalam setelah $B A B$ dan BAK tanpa mengeringkan organ genitalia. Hal ini setara dengan penelitian Mokodongan (2015) dalam Abrori et al., (2017) menyatakan bahwa lebih banyak remaja memiliki risiko tinggi akan mengalami masalah kesehatan reproduksi, ada $10 \%$ remaja yang sering menggunakan produk pembersih wanita, ada $17,59 \%$ remaja yang tidak mengeringkan genitalia eksterna setelah buang air kecil atau buang air besar dengan menggunakan tisu atau handuk kering. Selanjutnya 25,76\% 
remaja yang membersihkan genitalia eksterna dengan arah dari belakang ke depan, 17\% remaja yang sering menggunakan celana dalam ketat dalam aktivitas sehari-hari. 8,2\% remaja yang sering memakai celana dalam dengan bahan bukan katun 2,5\% remaja yang sering memakai bersama pakaian dalam dan handuk dengan orang lain.

Hal ini sesuai penelitian Suriani \& Hermansyah (2014) mengatakan bahwa masalah remaja dengan organ reproduksinya kurang mendapatkan perhatian karena umur relatif muda, masih dalam status pendidikan sehingga seolah-olah bebas dari kemungkinan menghadapi masalah penyulit dan penyakit yang berkaitan dengan alat reproduksinya.

Penelitian ini juga sesuai dengan penelitian Sori (2017) yang mengatakan bahwa kurangnya menjaga kebersihan organ vagina eksternal seperti seringnya penggunaan sabun pembersih kewanitaan, penggunaan alat pewangi didaerah kemaluan serta seringnya membiarkan organ intim dalam keadaan basah, misalnya setelah buang air kecil tidak dikeringkan mengakibatkan timbul beberapa penyakit kelamin seperti keputihan, kanker serviks, alergi, peradangan, infeksi saluran kemih.

Pada penelitian ini lebih banyak pengetahuan personal hygiene buruk dibandingkan kelompok intervensi. Hal ini sama dengan kelompok intervensi yang mana pengetahuan personal hygiene buruk dilihat dari hasil kuesioner, mereka mempunyai kebiasaan yang buruk terhadap personal hygiene terutama pada hygiene genitalia yang kurang diperhatikan kebersihannya. Penelitian ini selaras dengan Jurnal Yunaefi et al., (2016) yang mengatakan didapatkan hasil data statistik Indonesia 2012 dari 43,3 juta jiwa remaja berusia 14-24 tahun di Indonesia berpengetahuan tidak sehat. Dari hasil penelitian masih banyak remaja yang pengetahuan personal hygiene buruk dan dapat berdampak pada kesehatan termasuk kesehatan reproduksi.

Kesehatan reproduksi remaja sangatlah harus diperhatikan karena dengan kebersihan organ genitalia dapat mencegah dari berbagai penyakit yang dapat menyerang organ genitalia. Tetapi, nyatanya dalam penelitian yang telah dilakukan masih banyak terdapat remaja putri yang tidak tau bagaimana cara membersihkan organ genitalia yang baik dan benar.

4. Gambaran Pengetahuan Personal Hygiene Sesudah diberikan Perlakuan pada Kelompok Kontrol

Penelitian ini setara dengan Mokodongan (2015) dalam Jurnal Abrori et al., (2017) menyatakan bahwa lebih banyak remaja memiliki risiko tinggi akan mengalami masalah kesehatan reproduksi, ada $17,59 \%$ remaja yang tidak mengeringkan genitalia eksterna 
setelah buang air kecil atau buang air besar dengan menggunakan tisu atau handuk kering. Selanjutnya $25,76 \%$ remaja yang membersihkan genitalia eksterna dengan arah dari belakang ke depan, $17 \%$ remaja yang sering menggunakan celana dalam ketat dalam aktivitas sehari-hari. 8,2\% remaja yang sering memakai celana dalam dengan bahan bukan katun.

Pada penelitian ini saat pemberian leaflet pada remaja putri sebagian remaja tidak benar-benar membaca leaflet mereka hanya melihatnya saja, hanya beberapa yang benarbenar membaca leaflet yang telah diberikan. Ternyata setelah pemberian leaflet masih ada yang pengetahuan personal hygiene kategori buruk. Pemberian leaflet tidak terlalu berpengaruh untuk meningkatkan pengetahuan personal hygiene remaja putri karena mereka tidak ada interaksi diskusi dan sharing seperti pada kelompok intervensi yang diberikan peer group. Hasil penelitian ini bermanfaat mengetahui bahwa lebih baik pemberian pendidikan kesehatan dengan metode peer group dibandingkan pemberian leaflet saja.

5. Pengaruh Pendidikan Kesehatan Peer Group Terhadap Pengetahuan Personal Hygiene Remaja Putri pada Kelompok Intervensi

Dilihat dari hasil penelitian menggunakan kuesioner pada kelompok intervensi ternyata terdapat perbedaan pengetahuan personal hygiene yang signifikan antara sebelum dan sesudah diberikan Pendidikan kesehatan pada remaja putri. Penelitian ini dikuatkan oleh hasil penelitian Herniyatun, Astutiningrum dan Nurlaila, (2008) dalam Jurnal Ervyna, Utami \& Surasta (2015), bahwa model intervensi Pendidikan kesehatan untuk meningkatkan pengetahuan, sikap dan pengetahuan masyarakat untuk pencegahan kanker serviks merupakan model yang lebih efektif dan efisien yang perlu untuk dikembangkan.

Hal ini seperti dalam jurnal Suriani \& Hermansyah (2014) yang mengatakan bahwa penanganan yang dilakukan untuk mencegah masalah kesehatan reproduksi remaja salah satunya pendekatan pada kelompok sebaya (peer group). Kuatnya pengaruh kelompok sebaya (peer group) dikarenakan remaja lebih banyak berada diluar rumah bersama dengan teman-teman sebaya sebagai kelompok. Peer group diharapkan mampu tumbuh menjadi peer educator yang diharapkan dapat membahas dan menangani permasalahan kesehatan reproduksi remaja. Institusi sekolah merupakan jalur yang sangat potensial untuk melatih peer group ini, karena institusi sekolah ini sangat mempengaruhi kehidupan dan pergaulan remaja.

Penelitian ini seperti yang dikemukakan oleh Desmamita (2014), peer group merupakan salah satu agen sosialisasi bagi individu. Dalam kelompok inilah 
berlangsungnya penurunan nilai budaya suatu kebudayaan, norma, acuan bertingkah laku, sistem dan pola berfikir sekelompok masyarakat, dan sebagainya. Semakin dewasa seseorang maka akan semakin kuat pula pengaruh dari peer group, sehingga pengaruh dari keluarga akan semakin melemah. Menurut Ervyna, Utami \& Surasta (2015) dalam Jurnalnya, edukasi sebaya terhadap pengetahuan personal hygiene genetalia dapat dijadikan masukan untuk perencanaan pengembangan PKPR (Pelayanan Kesehatan Peduli Remaja) yakni pelatihan pendidik sebaya, yang merupakan upaya nyata melibatkan remaja secara aktif dengan melatih remaja menjadi kader kesehatan remaja dan pendidik sebaya ini akan berperan sebagai agent of change bagi teman sebayanya untuk berpengetahuan sehat.

Seperti yang dikemukakan Notoatmodjo (2007) dalam Jurnal Fatimah, Royhanaty \& Sawitry (2016) yaitu, pendidikan kesehatan adalah aplikasi atau penerapan pendidikan di dalam bidang kesehatan. Hasil (output) yang diharapkan dari suatu pendidikan kesehatan adalah pengetahuan kesehatan, atau pengetahuan untuk memelihara dan meningkatkan kesehatan yang kondusif . Peer group adalah salah satu ciri yang dibentuk dalam pengetahuan sosial dimana pengetahuan kelompok tersebut akan mempengaruhi pengetahuan serta nilai-nilai individu-individu yang menjadi anggotanya sehingga individu tersebut akan membentuk pola pengetahuan dan nilai-nilai yang baru.

Ternyata dengan pendidikan kesehatan dapat meningkatkan pengetahuan personal hygiene remaja putri yang ada di SMP 1 Muhammadiyah Banjarmasin. Saat penelitian terlihat bahwa responden yang melakukan pendidikan kesehatan dengan metode peer group sangat aktif bercerita masalah kesehatan reproduksi yang telah mereka alami. Hal ini menunjukkan bahwa pendidikan kesehatan dengan metode peer group dapat memperbaiki pengetahuan personal hygiene remaja putri di karenakan pada saat penelitian responden lebih banyak sharing atau bercerita dengan kelompoknya tentang masalahmasalah kesehatan reproduksi yang mereka pernah alami dan mereka saling memberikan masukan atau saran yang membuat mereka memahami tentang bagaimana pengetahuan personal hygiene yang baik dan benar. Selain itu, karena mereka memiliki usia yang kurang lebih sama jadi memudahkan mereka untuk saling bercerita dan tidak malu ataupun risih saat bercerita.

Penelitian ini menunjukkan bahwa pendidikan kesehatan dengan metode peer group dapat diaplikasikan remaja putri untuk dapat berbagi pengalaman dan pengetahuan 
dalam meningkatkan kesehatan reproduksi khususnya dalam personal hygiene dari yang remaja tidak tau menjadi tau dan mengaplikasikan pengetahuan personal hygiene yang baik dalam kesehariannya.

6. Pengaruh Pemberian Leaflet Terhadap Pengetahuan Personal Hygiene Remaja Putri pada Kelompok Kontrol

Pada hasil penelitian ini pengetahuan personal hygiene remaja putri sebelum dan sesudah diberikan leaflet mengalami peningkatan, tetapi tidak terdapat pengaruh dengan pemberian leaflet tersebut. Dari hasil penelitian menggunakan kuesioner antara sebelum dan sesudah pemberian leaflet dari 15 responden ada 3 responden yang nilai kuesionernya mengalami penurunan, 4 responden yang nilainya tetap tidak terdapat perubahan dan 8 responden yang nilanya meningkat tetapi tidak terlalu jauh beda dengan nilai sebelumnya. Kemudian dari hasil kuesioner juga didapatkan masih ada remaja putri yang kurang memperhatikan kebersihan genitalianuya, seperti membasuh organ genitalia tidak dari depan ke belakang dan tidak mengeringkan organ genitalia setelah $B A B$ dan BAK, kemudian masih ada yang jarang mengganti celana dalam.

Penelitian ini setara dengan Mokodongan (2015) dalam Jurnal Abrori et al., (2017) menyatakan bahwa lebih banyak remaja memiliki risiko tinggi akan mengalami masalah kesehatan reproduksi, ada 17,59\% remaja yang tidak mengeringkan genitalia eksterna setelah buang air kecil atau buang air besar dengan menggunakan tisu atau handuk kering. Selanjutnya $25,76 \%$ remaja yang membersihkan genitalia eksterna dengan arah dari belakang ke depan, $17 \%$ remaja yang sering menggunakan celana dalam ketat dalam aktivitas sehari-hari. 8,2\% remaja yang sering memakai celana dalam dengan bahan bukan katun.

Pada penelitian ini saat pemberian leaflet pada remaja putri sebagian remaja tidak benar-benar membaca leaflet mereka hanya melihatnya saja, hanya beberapa yang benarbenar membaca leaflet yang telah diberikan. Ternyata setelah pemberian leaflet masih ada yang pengetahuan personal hygiene kategori buruk. Pemberian leaflet tidak terlalu berpengaruh untuk meningkatkan pengetahuan personal hygiene remaja putri karena mereka tidak ada interaksi diskusi dan sharing seperti pada kelompok intervensi yang diberikan peer group. Hasil penelitian ini bermanfaat mengetahui bahwa lebih baik pemberian pendidikan kesehatan dengan metode peer group dibandingkan pemberian leaflet saja tanpa ada pemberian materi dari peer educator.

\section{KESIMPULAN}

Terdapat Pengaruh Pendidikan Kesehatan dengan metode Peer Group Terhadap 
Pengetahuan Personal Hygiene Remaja Putri di SMP 1 Muhammadiyah Banjarmasin dibuktikan dengan adanya perbedaan nilai pengetahuan personal hygiene antara sebelum dan sesudah diberikan pendidikan kesehatan dengan metode peer group pada kelompok intervensi.

\section{DAFTAR PUSTAKA}

Abrori, Hernawan, A. D., \& Ermulyadi. (2017). Faktor Yang Berhubungan Dengan Kejadian Keputihan Patologis Siswi SMAN 1 Simpang Hilir Kabupaten Kayong Utara. Unnes Journal of Public Health Vol. 6 No. 1, 2017: 25-34.

Agustiana, R. D. (2015). Pengaruh Teman Sebaya, Lingkungan Keluarga dan Motivasi Belajar terhadap Disiplin Belajar Akuntansi Siswa Kelas XI SMK Gatra Praja Pekalongan Tahun Ajaran 2014/2015. Skripsi, Universitas Negeri Semarang

Atapukang, F., \& Lestari, S. (2017). Hubungan Tingkat Pengetahuan Remaja Putri Tentang Vulva Hygiene Dengan Kejadian Keputihan Di SMP Muhammadiyah 1 Yogyakarta.

Aulia, F. I., Muhlisin, H. M., \& Kartinah. (2014). Pengaruh Pendidikan Kesehatan Tentang Personal Hygiene Terhadap Pengetahuan Dan Sikap Di SDN Rembes 1 Dusun Watugimbal Kecamatan Beringin Kabupaten Semarang.

Desmarnita, U., Djuwitaningsih, S., \& Rochimah. (2014). Pengaruh Pendidikan Kesehatan Metode Peer Group Terhadap Pengetahuan Dan Sikap Remaja Putri Tentang Kesehatan Reproduksi. JKep. Vol. 2 No. 3 Nopember 2014, hlm 55-62.

Ervyna, A., Utami, A. S., \& Surasta, W. (2015). Pengaruh Peer Education Terhadap Perilaku Personal Hygiene Genetalia dalam Pencegahan Kanker Serviks Pada Remaja Putri di SMP Negeri 10
Denpasar. Coping Ners Journal, Vol. 3, No. 2, Edisi Mei-Agustus 2015, hlm 6167

Fatimah, N., Royhanaty, I., \& Sawitry. (2016). Pengaruh Pendidikan Kesehatan Metode Peer Group Tentang Menstruasi Terhadap Kesiapan Menghadapi Menarche Pada Siswi SD Kelas V Di SD Pundenarum I Kecamatan Karangawen Kabupaten Demak. Jurnal Terpadu IImu Kesehatan, Volume 6, No 1, Mei 2016, hlm 01-117.

Fitria, R. D., Rosra, M., \& Mayasari, S. (2017). Pengaruh Pergaulan Teman Sebaya Terhadap Motivasi Belajar Siswa.

Handayani, S., Cahyo, K., \& Indraswari, R. (2017). Faktor-Faktor Yang Berhubungan Dengan Perilaku Personal Hygiene Remaja Putri Dalam Penanganan Dan Pencegahan Keputihan Pada Siswi SMK Negeri 11 Semarang. Jurnal Kesehatan Masyarakat (e-Journal) Volume 5, Nomor 3, Juli 2017.

Isro'in, L., \& Andarmoyo, S. (2012). Personal Hygiene Konsep, Proses Dan Aplikasi Dalam Praktik Keperawatan. Yogyakarta: Graha IImu.

Karyati, A., Suriadi, \& Febriyanti, T. R. (2014). Korelasi Antara Perilaku Vulva Hygiene Dengan Kejadian Keputihan Pada Mahasiswi Prpgram Studi Keperawatan Fakultas Kedokteran Universitas Tanjungpura Pontianak.

Mardalena, R. M., Sanusi, S. R., \& Asfriyati. (2015). Hubungan Pengetahuan Dan Sikap Dengan Tindakan Kebersihan Organ Genitalia Eksterna Sebagai Upaya Pencegahan Keputihan Pada Mahasiswi Fakultas Kesehatan Masyarakat Universitas Sumatera Utara Tahun 2015.

Maryunani, A. (2013). Perilaku Hidup Bersih Dan Sehat (PHBS). Jakarta: CV. Trans Info Media.

Murti, H., \& Lutfiyati, A. (2017). Hubungan Perilaku Menjaga Kebersihan Genitalia Dengan Kejadian Keputihan Pada Siswi SMAN 1 Galur. Skripsi, Sekolah Tinggi IImu Kesehatan Jenderal Achmad Yani Yogyakarta. 
Nanlessy, D. M., Hutagaol, E., \& Wongkar, D. (2013). Hubungan Antara Pengetahuan Dan Perilaku Remaja Puteri Dalam Menjaga Kebersihan Alat Genitalia Dengan Kejadian Keputihan Di SMA Negeri 2 Pineleng. E-journal Keperawatan (e-Kp) Volume 1. Nomor 1 Agustus 2013.

Nur, H. A. (2018). Hubungan Persepsi, Sikap, dan Perilaku Remaja Putri Tentang Personal Hygiene Genitalia dengan Kejadian Fluor Albus (Keputihan). Jurnal Profesi Keperawatan Vol. 5 No. 1 Januari 2018 hlm 1-13.

Nurhayati, A. (2013). Hubungan Pengetahuan, Sikap dan Perilaku Vaginal Hygiene Terhadap Kejadian Keputihan Patologis Pada Remaja Putri Usia 13-17 Tahun Di Daerah Pondok Cabe Hilir.

Pratiwi, R. T., Mediastuti, F., \& Winarsih. (2014). Diskusi Melalui Peer Group (Teman Sebaya) Terhadap Konsep Diri Remaja Tentang Perilaku Seksual. Jurnal IImu
Kebidanan, Volume II, Nomor 3, Desember 2014.

Sari, P. M. (2016). Hubungan Antara Pengetahuan Dan Sikap Remaja Dengan Kejadian Fluor Albus Remaja Putri SMKF X Kediri. Jurnal Wiyata, Vol. 3 No. 1 Tahun 2016, hlm 1-4.

Sori, M. M. (2017). Pengaruh Pendidikan Kesehatan Menggunakan Booklet dalam Meningkatkan Pengetahuan Remaja Putri Mengenai Kebersihan Organ Genitalia Eksterna Di SMAN 1 Sine Kabupaten Ngawi.

Suriani, \& Hermansyah. (2014). Pengaruh Peer Group Terhadap Peningkatan Pengetahuan Kesehatan Reproduksi Remaja. Jurnal Ilmu Keperawatan.

Tulas, V. D., Kundre, R., \& Bataha, Y. (2017). Hubungan Perawatan Luka Perineum Dengan Perilaku Personal Hygiene Ibu Post Partum Di Rumah Sakit Pancaran Kasih GMIM Manado. e-Journal Keperawatan (e-Kp) Volume 5 Nomor 1, Februari 2017, hlm 1-9. 